Review article

\title{
Legislation, regulation and policies issues of orphan drugs in developed countries from 2010 to 2016
}

\author{
Petra Maresova, Blanka Klimova, Kamil Kuca* \\ University of Hradec Kralove, Faculty of Informatics and Management, Hradec Kralove, Czech Republic
}

\section{A R T I C L E I N F O}

\section{Article history:}

Received 8 October 2017

Received in revised form 9 December 2017

Accepted 26 April 2018

Available online 1 May 2018

\section{Keywords:}

Legislation

Policy issues

Rare diseases

Orphan drugs

Europe

\section{A B S T R A C T}

The purpose of this study is to evaluate current legislative policies and regulations with respect to the use of orphan drugs, to emphasize strengths and weaknesses of these policies in the period of 2010-2016 in European countries, especially in relation to the objectives set by the European Council in 2009. This was done by the method of literature search in the databases PubMed, Scopus, ScienceDirect, and Web of Science from 2010 to 2016. The findings show a lack of polices for the appraisal and reimbursement of orphan drugs, a lack of uniform European legislation and different orphan drugs expenditure.

(c) 2018 Faculty of Health and Social Sciences, University of South Bohemia in Ceske Budejovice. Published by Elsevier Sp. z o.o. All rights reserved.

\section{Introduction}

The term orphan disease was firstly coined by Melnick (1954), who called new viruses, which occur among patients suspected of having non-paralytic poliomyelitis, orphan viruses. An orphan disease may be a rare disease (RD) or a common disease that has been ignored (such as cholera or typhoid) because it is far more prevalent in developing countries than in the developed world. Its prevalence in Europe is considered to be less than five people in 10,000 (European Commission, 2012). Per capita it is less than one patient out of 2000. The same number is true for Australia. In the USA, the incidence of orphan diseases per capita is slightly higher, 1 in 1500 , while in Japan it is 1 in 2500 . Thus, surprisingly, RDs are quite common. In fact, they are more frequent than diabetes and as common as asthma (Elliot and Zurynski, 2015). Unfortunately, RDs are complex and chronic and only a small number of these diseases can be treated. Therefore, in other cases there is a long-term palliative treatment.

Nowadays, there are more than 8000 RD. $80 \%$ of them are of genetic origin, while the rest are the results of infections, allergies and environmental causes, or are degenerative. Although RDs are typical of both adults and children, their incidence is much higher

\footnotetext{
* Author for correspondence: University of Hradec Kralove, Faculty of Informatics and Management, Sokolska 581, 500 05, Hradec Kralove, Czech Republic.

E-mail address: kamil.kuca@uhk.cz (K. Kuca).
}

among children since $75 \%$ of RDs occur among children till the age of 10 (Maresova et al., 2015).

In comparison with common diseases, these RDs are connected with complications such as high costs of treatment and legislative conditions. Currently, the highest costs of orphan drugs (ODs) on the total drug expenditure are in France, Belgium, UK, Spain, and Italy (Hughes-Wilson et al., 2012). For example, in their study, Denis et al. (2010), focused on the situation in Belgium and state that in the course of five years 2008-2013, the costs on ODs would increase from $5 \%$ to $10 \%$. This increase is based on the estimation that 10 new ODs would reach the market each year. This would represent almost $4 \%$ of the costs of all drug reimbursements to the budget. These values are among the higher ones in the EU countries. In addition, the study by Kanters et al. (2014) describes the budget impact of ODs in the Netherlands in the period of 2006 to 2012. The findings show that the number of ODs, patients and costs significantly increased over a period of six years. However, the growth rate of public expenditure slowly decreased at the end of the reference period. In addition, the research studies conducted in Sweden and France predicted the growth of costs on these drugs (Hutchings et al., 2014). The main reason of these increasing costs was the amount of new Orphan Medicinal Products (OMPs) obtaining the OMP designation. Nevertheless, these studies illustrate that ODs in comparison with other drugs do not represent any immediate threat for the system of public health insurance. Despite this fact, the issue of expenditure and approval of payment from the public 
sources is being discussed in each country in connection with the threat of high expenditure.

Orphan product designation was first introduced in the EU in 2000 under the Regulation (EC) No. 141/2000. The regulation established the procedure for orphan product designation. Detailed incentives for products granted orphan designation and formed the Committee for Orphan Medicinal Products (COMP) which is charged with reviewing applications for the designation (Mezher, 2015).

RDs and ODs are a highly important issue. This fact can be illustrated by the current focus of the Maltese Presidency of the EU Council. They aim "to focus on enhancing cross-border cooperation through the promotion of centres of excellence, for example in the area of rare diseases" (European Commission, 2017). One of the major goals in the programme of Maltese presidency concerns health. Specifically, the programme states that "the Health Systems of Member States face common challenges which can be mitigated when Member States work together in synergy. The Maltese Presidency will work to identify mechanisms of voluntary structured cooperation between health systems driven by Member States, to further support Member States and provide tangible benefits for health professionals and patients. The two areas which have been identified are: structured cooperation to improve access to innovative health technologies for RDs in the EU and cooperation to address the EU health workforce challenges, with a focus on that associated with the provision of highly specialised health services" (European Commission, 2016). The main motivation stems, on the one hand, from the efforts to increase the quality of life and the related impact of treatment and, on the other hand, the cost of illness in the context of limited financial resources of governments in developed countries, including the expected impact of new treatments on public budget.

The purpose of this review study is, on the basis of available studies, to evaluate current legislative policies and regulations with respect to the use of ODs, to emphasize strengths and weaknesses of these policies in the period of 2010-2016 in European countries, especially in relation to the objectives set by the European Council in 2009.

\section{Materials and methods}

The methodology of this review study is based on Moher et al. (2009). The main methods included a literature review of the fulllength research studies examining the issue of orphan drug legislation. This was done by searching databases PubMed (www. ncbi.nlm.nih.gov/pubmed), Scopus (https://www.scopus.com), ScienceDirect (https://www.sciencedirect.com/) and Web of Science (https://pcs.webofknowledge.com) from 2010 to 2016 for the keywords: ODs AND European legislative, or ODs AND legislative or rare diseases AND regulations. The search was limited to the years of 2010-2016 only because in June 2009 the European Council adopted the Recommendation supporting adoption of national plans and strategies for responding to RDs. The study was included if it explored the research issue, i.e. the OD legislation, if it was a full-length study written in English, and if it covered the designated period from 2010 till 2016.

Articles that met the inclusion criteria of the quality of research papers were evaluated according to adequate description of the theoretical framework, background, and methodology (Hutchings et al., 2014; Mays and Pope, 2000). For those papers that fulfilled the criteria for quality, data was extracted according to the following content: date published, study funding source, possible conflicts of interest, county, study objectives, application of tool, description of tool or approach, all stakeholders involved, literature search incorporated and results of implementation.
Altogether 622 were identified: in the database PubMed it was 282 studies, ScienceDirect 279 studies, Scopus 41 studies, and in Web of Science 20 studies.

The selection procedure of the final number of studies was done in the following four steps:

- Identification (identification of the key words and consequently; available relevant sources);

- Duplication check (114 were excluded);

- Assessment of relevancy (verification on the basis of the title 211 excluded) and abstracts (203 excluded), only the studies which evaluate the present legislation, availability of drugs in individual countries, and political framework remained;

- Full text analysis.

The criteria for the content analysis were as follows:

- Studies for the last six years;

- Studies dealing with legislative changes of the development of distribution and sale of ODs;

- Studies focused on Europe and/or the USA as the main leaders in this field.

The selection process of the research studies is illustrated in Fig. 1 below.

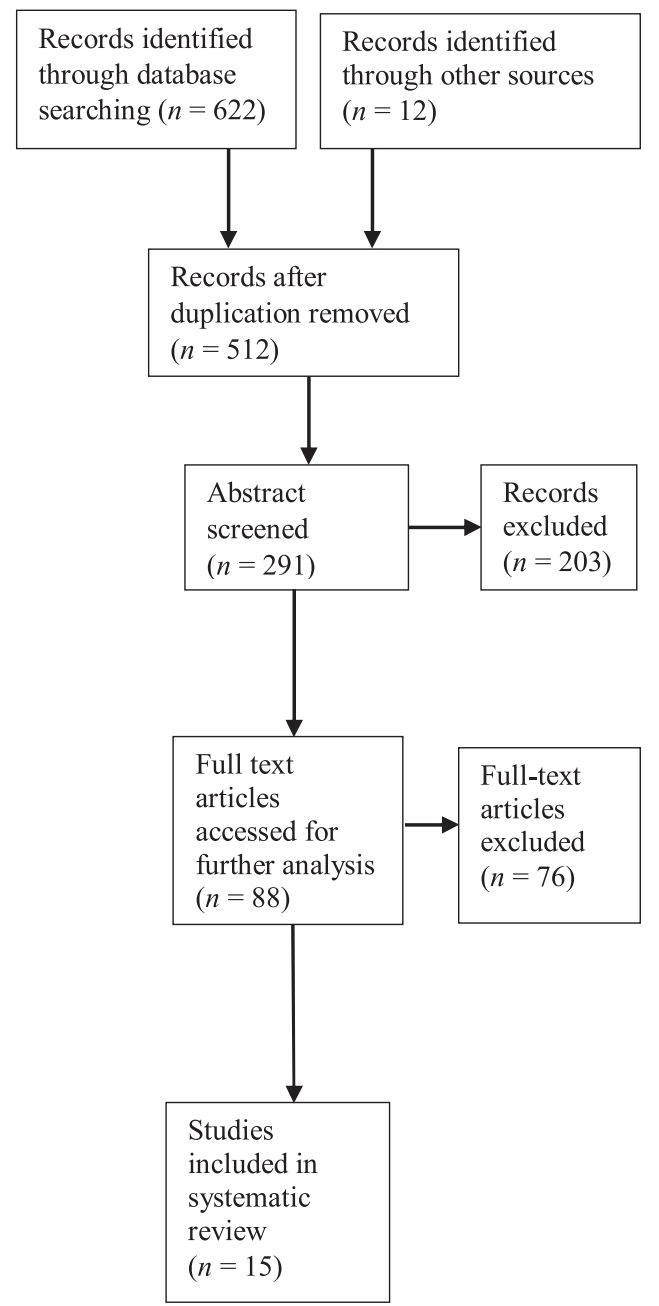

Fig. 1. Results of the selection procedure. 


\section{Results}

The search retrieved 622 papers in total, out of which 15 fulfilled the inclusion criteria (PRISMA flowchart, Fig. 1). The results from the selected studies indicate that there is significant progress in the legislative processes as far as ODs are concerned. This is especially connected with the implementation of OD Act (1983) and the Regulation on Orphan Medicinal Products No. 141/ 2000, which has stimulated the development and marketing of new ODs (Gammie et al., 2015; Heemstra et al., 2008; Lenk and Duttge, 2014; Logviss et al., 2014; Zelei et al., 2016). In addition, more research has been conducted thanks to the innovations into the pharmaceutical development (Heemstra et al., 2008). Overall, the European countries attempt to follow the successful legislative trends set by the USA in the field of ODs. Rodwell and Aymé (2015) in their study summarized the main achievements. They claim that apart from the introduction of the Regulation on Orphan Medicinal Products, which led to the development of over 80 new therapies for RDs, national strategies were developed. Moreover, an improved codification for RDs and RDs patient registries was developed, or the Expert Group on RDs was established.

On the contrary, there are still several common problems with respect to the OD legislation. The most serious issue is a lack of uniform European legislation. As Zelei et al. (2016) put it, many European countries do not have specific polices for the appraisal and reimbursement of ODs. This results in many patients across Europe who do not see any benefit from the orphan product legislation. Furthermore, patient access to ODs varies across different European countries. This is also confirmed by other research studies (Côté and Keating, 2012; Hansen, 2010; Picaveta et al., 2012; Štěrba et al., 2014). For instance, Logviss et al. (2014), state that in Latvia there are no official designated centres of expertise or specific registers for RDs. Therefore, more joint initiatives both at national and European level are required. In fact, according to the latest accessible data, the situation in most European countries still differs (European Commission, 2016). Since the number of patients suffering from RDs is low, the negative impact on the public expenditure has not been proved yet.

Côté and Keating (2012) summarized the main negative aspects of the European legislative processes in the field of ODs. They are as follows: 1) doubts about the equity of access to drugs, 2) forcing the third-party payers to make drugs accessible even if the prices of drugs are believed to be disproportionate to the clinical effects obtained. Hyry et al. (2016) argue that survival of the orphan drug legislation is at risk if a solution is not found.

Therefore, Dunoyer (2011) suggests three approaches which may facilitate regulation and access to treatments for RDs:

- Improving understanding of RDs;

- Applying innovative strategies in clinical trials since RCT are not feasible in RD;

- Establishing a dialogue between industry, regulators and patent organizations to generate optimal approaches for clinical development and patient access.

Hollak et al. (2015) propose the system of post-authorization assessment for ODs to be reformed to address the issues mentioned above. In addition, fast access to high quality data is important for the improvement of treatment and management of cost-effectiveness. Finally, Rollet et al. (2013) call for broader understanding by clinicians, public and policy makers of the complexity of clinical programs to introduce orphan medicinal products to market. They also emphasize that more research and development are needed in the field of RDs.

\section{Discussion}

Discussion of the results in the context of the European Council held in 2009

In June 2009, the Council adopted the Recommendation Supports Adoption of National Plans and Strategies for responding to RDs and the Member States should do the following:

- Elaborate and adopt a plan or strategy by the end of 2013 at the latest to guide and structure actions in RDs within their health and social systems;

- Integrate initiatives at local, regional and national levels;

- Explore measures for RDs in other public health strategies, to ensure that patients have access to high quality care, including diagnostics and treatment.

On the basis of the selected studies, which are the only public source of data and information about the real situation in these countries, the strengths of the OD legislation can be summarized as follows:

- Most of the EU countries possess OD legislation;

- There is a faster process of approving ODs in Europe than in the USA;

- The EU regulation of ODs promotes the development of new treatments of orphan diseases;

- There is an increase in the number of approved and accessible ODs;

- There is a demand for new and safe drugs for children.

On the contrary, there still exist certain barriers which hinder the whole process of OD legislation in Europe, which is reflected in the lack of specific policies for the appraisal and reimbursement of ODs, inequality in patient access to ODs across European countries, or different Health Technology Assessment (HTA) criteria in individual European countries. Moreover, there is a general feeling for a more coordinated cooperation of the interested stakeholders, as well as for higher integration of the European legislation into the legislation of the European countries.

The fact that the countries should work on their set goals is also confirmed by the current state of their national strategies for RDs. According to the website of the European Commission (European Commission, 2016), it is evident that 25 countries set their national strategic plan. Their availability, however, varies; some still exist only in national languages, others are obsolete (Table 1 ).

Table 1 above shows that only three countries: Austria, Czech Republic and Portugal have defined current and valid time horizon of their national strategies.

Although there is considerable progress in the legislative processes as far as ODs are concerned, which is especially connected with the implementation of OD Act (1983) and the Regulation on Orphan Medicinal Products No. 141/2000, the situation in most of the European countries still differs. Since the number of patients suffering from RDs is low, the European Commission attempts to increase the awareness of RDs, their diagnosis, treatment and management in the following ways: launching national strategies for RDs in the EU countries, whose goal is to guarantee that patients with RDs have universal access to high quality care, including diagnostics, therapies and medicinal products for RDs; conducting research of the causes and treatments for RDs or deepening collaboration with patient organizations for RDs.

These aims reflect essential shortcomings in many European countries, which include an insufficient identification of RDs within the system of the International Classification of Diseases, 
Table 1

National strategies for RDs in European countries.

\begin{tabular}{lll}
\hline Country & Time period & Availability (Language) \\
\hline Austria & $2014-2018$ & German \\
Belgium & 2010 & French in 2013 \\
& 2013 & English, French in 2010 \\
Bulgaria & $2009-2013$ & Bulgarian, English \\
Croatia & undefined & Croatian \\
Cyprus & 2012 & Greek \\
Czech Republic & $2010-2020$ & Czech, English \\
France & $2010-2014$ & French \\
Germany & 2013 & German, English \\
Greece & $2008-2012$ & Greek \\
Hungary & 2020 & English \\
Ireland & undefined & English \\
Italy & $2013-2016$ & Italian \\
Latvia & $2013-2015$ & Latvian \\
Lithuania & undefined & Lithuanian \\
Luxembourg & 2011 & Luxemburgish \\
Portugal & $2008-2018$ & Portuguese only \\
Romania & $2010-2014$ & English, Romanian \\
Slovak Republic & $2012-2013$ & Slovak, English \\
Slovenia & undefined & English, Slovenian \\
Spain & undefined & English, Spain \\
The Netherlands & undefined & English, Dutch \\
United Kingdom & 2013 & English \\
\hline
\end{tabular}

Note: Based on the European Commission (2016).

shortcomings in their early diagnosis and treatment, inequality and insufficient quality of the provided services, shortcomings in research and data collection, as well as ineffectiveness of care of patients with RDs. Furthermore, there is a need of fast access to high quality data, which is significant for the improvement of treatment and management of cost-effectiveness, as well as a need of broader understanding by clinicians, the public and policy makers of the complexity of clinical programs to introduce orphan medicinal products to market.

The positive aspect is that in many EU countries there is a significant increase in the neonatal screening and cooperation across individual health centres and associations for RDs. In any case, the concept of RDs should be eventually incorporated into the legislation of all European countries and a specific legislative framework for setting prices and reimbursement for OD should be set. Another task is the codification of RDs. A better codification will enable a better patient monitoring. In addition, it is necessary to centralize diagnostics and treatment of individual diagnostic groups of RDs and connect the care with the reimbursement of health insurance companies.

The support of patients with RDs and their caregivers is not the only research challenge in the area of RDs. It is also the identification and analysis of the data concerning the quality of patient's life and cost-effectiveness of care and treatment. Partial issues, which should be solved in this respect, are as follows:

- Specification of medical and social needs of patients;

- Description of the current level of knowledge in the area of RDs among patients;

- Definition and unification of terminology in monitoring health costs;

- Specification of the process of data collection and also of the key items of direct and indirect costs.

In the case of the implementation of the above mentioned items, development and marketing of new ODs might be stimulated. In addition, more research may be conducted thanks to the innovations into the pharmaceutical development. All this will require increased public health expenditure. It is therefore essential to solve the issues of the optimization of decision-making processes about the amount and structure of expenditure.

\section{Conclusion}

As it can be seen from the findings of this review study, the issue of legislation, regulation and policies issues of ODs in developed countries is quite complex. On the one hand, thanks to the implementation of OD Act and the Regulation on Orphan Medicinal Products, there has been an increase in the research, development and marketing of new ODs. On the other hand, there is a lack of specific policies for the appraisal and reimbursement of ODs, inequality in patient access to ODs across European countries, or different HTA criteria in individual European countries. Moreover, there is an urgent call for a more coordinated cooperation of the interested stakeholders, as well as for higher integration of the European legislation into the legislation of the European countries.

\section{Conflict of interests}

The authors have no conflict of interests to declare.

\section{Acknowledgements}

This study was supported by the project Excellence 2018 and SPEV 2018 (University of Hradec Kralove, Faculty of Informatics and Management) and internal project of Faculty of Informatics and Management.

\section{References}

Štěrba, J., Štěrbová, S., Kodytková, D., Valík, D., Demlová, R., 2014. Klinické hodnocení nových léčiv u vzácných diagnóz v onkologii -současná situace v Evropě a u nás. Vnitřní lékařství 60 (2), 80-85.

Côté, A., Keating, B., 2012. What is wrong with orphan drug policies? Value Health 15 (8), 1185-1191.

Denis, A., Mergaert, L., Fostier, C., Cleemput, I., Simoens, S., 2010. Budget impact analysis of orphan drugs in Belgium: Estimates from 2008 to 2013. J. Med. Econ. 13 (2), 295-301.

Dunoyer, M., 2011. Accelerating access to treatments for rare diseases. Nat. Rev. Drug Discov. 10 (7), 475-476.

Elliot, E.J., Zurynski, Y.A., 2015. Rare diseases are a common problem for clinicians. R. Aust. Coll. General Pract. 44 (9), 630-633.

European Commission, 2012. Public Health. [online]. [cit. 2015-11-26]. Available at: http://ec.europa.eu/health/rare_diseases/policy/index_en.htm.

European Commission, 2016. National Plans or Strategies for Rare Diseases. [online] [cit. 2017-01-26]. Available at: https://ec.europa.eu/health/rare_diseases/ national_plans/detailed_en.

European Commission, 2017. Programme of the Maltese Presidency of the Council of the European Union. [online]. [cit. 2017-02-26]. Available at: http://www. eu2017.mt/en/Documents/NationalProgramme_EN.pdf.

Gammie, T., Lu, C.Y., Babar, Z.U.-D., 2015. Access to orphan drugs: a comprehensive review of legislations, regulations and policies in 35 countries. PLoS One 10 (10), e0140002. doi:http://dx.doi.org/10.1371/journal.pone.0140002.

Hansen, J.C., 2010. Rare Diseases \& Orphan Drugs, a Comprehensive Approach of Strategic Perspectives. Article UK JIMS, 2010. [online] [cit. 2017-02-26]. Available at: https://www.researchgate.net/profile/Jan_Cedric_Hansen3/ publication/272254495_Rare_Diseases_and_Orphan_Drugs_A_ comprehensive_approach_of_strategic_perspectives/links/ 57bc054d08ae51eef1f4ea72. pdf?origin = publication_detail.

Heemstra, H.E., de Vrueh, R.L., van Weely, S., Büller, H.A., Leufkens, H.G., 2008 Orphan drug development across Europe: bottlenecks and opportunities. Drug Discovery Today 13 (15-16), 670-676.

Hollak, C.E., Biegstraaten, M., Levi, M., Hagendijk, R., 2015. Post-authorisation assessment of orphan drugs. Lancet 386 (10007), 1940-1941.

Hughes-Wilson, W., Palma, A., Schuurman, A., Simoens, S., 2012. Paying for the orphan drug system: break or bend? Is it time for a new evaluation system for payers in Europe to take account of new rare disease treatments? Orphanet J. Rare Dis. 7, 74.

Hutchings, A., Schey, C., Dutton, R., Achana, F., Antonov, K., 2014. Estimating the budget impact of orphan drugs in Sweden and France 2013-2020. Orphanet J. Rare Dis. 9 (1), 22.

Hyry, H.I., Cox, T.M., Roos, J.C., 2016. Saving orphan drug legislations: misconceptions and clarifications. Expert Rev. Pharmacoecon. Outcomes Res. 16 (1), 111-117. doi:http://dx.doi.org/10.1586/14737167.2016.1141052.

Kanters, T.A., Steenhoek, A., Hakkaart, L., 2014. Orphan drugs expenditure in the Netherlands in the period 2006-2012. Orphanet J. Rare Dis. 9, 154.

Lenk, C., Duttge, G., 2014. Ethical and legal framework and regulation for off-label use: european perspective. Ther. Clin. Risk Manage. 10, 537-546. 
Logviss, K., Krievins, D., Purvina, S., 2014. Rare diseases and orphan drugs: latvian story. Orphanet J. Rare Dis. 18 (9), 147. doi:http://dx.doi.org/10.1186/s13023014-0147-z.

Maresova, P., Mohelska, H., Kuca, K., 2015. Cooperation policy of rare diseases in the European Union. Proc. -Soc. Behav. Sci. 171, 1302-1308.

Mays, N., Pope, C., 2000. Qualitative research in health care: assessing quality in qualitative research. BMJ 320 (7226), 50-52.

Melnick, J.L., 1954. Application of tissue culture methods to epidemiological studies of poliomyelitis. Am. J. Public Health 44 (5), 571-580.

Mezher, M., 2015. Orphan Drugs in the EU: a Record-breaking Year. [online]. [cit. 2016-02-26]. Available at: http://www.raps.org/Regulatory-Focus/News/2015/ 01/13/21063/Orphan-Drugs-in-the-EU-A-Record-Breaking-Year/\#sthash. Ccsqg94W.dpuf.
Moher, D., Liberati, A., Tetzlaff, J., Altman, D.G., 2009. The PRISMA Group. Preferred reporting items for systematic review and meta-analysis: the PRISMA statement. PLoS Med. 6 (6), e1000097.

Picaveta, E., Cassiman, D., Simoens, S., 2012. Evaluating and improving orphan drug regulations in Europe: a Delphi policy study. Health Policy 108 (1), 1-9.

Rodwell, C.H., Aymé, S., 2015. 2015. Rare disease policies to improve care for patients in Europe. Biochim. Biophys. Acta 1852, 2329-2335.

Rollet, P., Lemoine, A., Dunoyer, M., 2013. Unstainable rare diseases business and drug access: no time for misconceptions. Orphanet J. Rare Dis. 8, 109. doi:http:// dx.doi.org/10.1186/1750-1172-8-109.

Zelei, T., Molnar, M.J., Szegedi, M., Kalo, Z., 2016. Systematic review on the evaluation criteria of orphan medicines in Central and Eastern European countries. Orphanet J. Rare Dis. 11, 72. doi:http://dx.doi.org/10.1186/s13023-016-0455-6. 